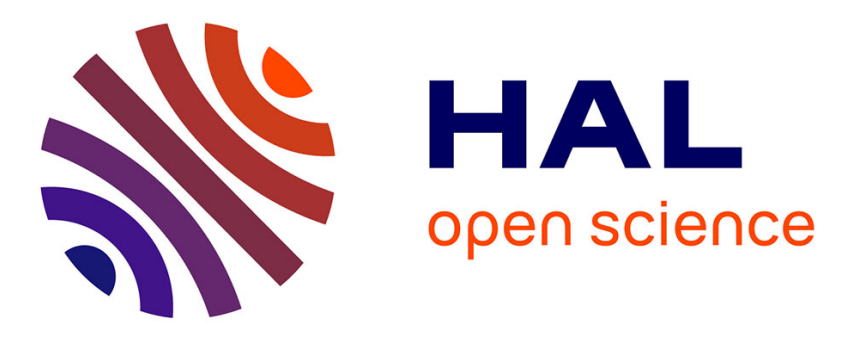

\title{
The effect of palladium and platinum doping on the structure, stability and optical properties of germanium clusters: DFT study of PdGen and PtGen ( $\mathrm{n}=1-20)$ clusters
}

Mustapha Lasmi, Sofiane Mahtout, Franck Rabilloud

\section{To cite this version:}

Mustapha Lasmi, Sofiane Mahtout, Franck Rabilloud. The effect of palladium and platinum doping on the structure, stability and optical properties of germanium clusters: DFT study of PdGen and PtGen $(\mathrm{n}=1-20)$ clusters. Computational and Theoretical Chemistry, 2020, 1181, pp.112830. 10.1016/j.comptc.2020.112830 . hal-02634488

\author{
HAL Id: hal-02634488 \\ https://hal.science/hal-02634488
}

Submitted on 12 Mar 2021

HAL is a multi-disciplinary open access archive for the deposit and dissemination of scientific research documents, whether they are published or not. The documents may come from teaching and research institutions in France or abroad, or from public or private research centers.
L'archive ouverte pluridisciplinaire HAL, est destinée au dépôt et à la diffusion de documents scientifiques de niveau recherche, publiés ou non, émanant des établissements d'enseignement et de recherche français ou étrangers, des laboratoires publics ou privés. 


\title{
The Effect of Palladium and Platinum Doping on the Structure, Stability and Optical Properties of Germanium clusters: DFT study of PdGe $\mathbf{P}_{n}$ and PtGe $_{n}(n=1-20)$ clusters
}

\author{
Mustapha LASMI ${ }^{a}$, Sofiane MAHTOUT ${ }^{a}$ and Franck RABILLOUD ${ }^{b}$ \\ ${ }^{a}$ Laboratoire de Physique Théorique, Faculté des Sciences Exactes, Université de Bejaia, \\ 06000 Bejaia, Algérie, \\ ${ }^{b}$ Univ Lyon, Université Claude Bernard Lyon 1, CNRS, Institut Lumière Matière, F-69622, \\ Villeurbanne, France \\ Corresponding authors: mahtout_sofiane@yahoo.fr,franck.rabilloud@univ-lyon1.fr
}

\begin{abstract}
Structural, electronic and optical properties of germanium clusters doped with palladium and platinum atoms $\mathrm{MGe}_{\mathrm{n}}(\mathrm{M}=\mathrm{Pd}, \mathrm{Pt}$ and $\mathrm{n}=1-20)$ are investigated in the framework of the densityfunctional theory. From $n \geq 10$ or 11, the cage-like structures where the doping atom is totally encapsulated inside a $\mathrm{Ge}_{\mathrm{n}}$ cage are favored. Relative stabilities of different $\mathrm{MGe}_{\mathrm{n}}$ clusters have been analyzed from the average binding energies, second energy differences, HOMO-LUMO gap, and the vertical ionization potential and electronic affinity. Our results show that the clusters of $\mathrm{MGe}_{\mathrm{n}}(\mathrm{M}=\mathrm{Pd}, \mathrm{Pt})$ with $\mathrm{n}=10,12,16$ and 18 exhibit relative high stability. Optical absorption spectra are predicted to be unable to discriminate the endohedral and exohedral structures.
\end{abstract}

\section{Introduction}

During the last decade, many efforts have been devoted to investigate the properties of pure or metal-doped germanium clusters due to their potential uses as assembled nanomaterials in the field of semiconductor materials and nanoelectronics. Recently, a number of experimental and theoretical studies have demonstrated that adding a metal atom in small germanium clusters could change dramatically their structural, electronic, magnetic and optical properties. [1-32] Particularly, in some cases the hybridization of orbitals and the pooling of valence electrons can stabilize germanium cages thanks to the encapsulation of the metal atom which absorbs the dangling bonds responsible of the instability of pure semiconductor clusters. [3-7]

Several transition metal (TM) atoms such as $\mathrm{Cu}, \mathrm{Ni}, \mathrm{Sc}$, Ti and $\mathrm{V}$ were showed to stabilize the host structure when they are encapsulated by germanium clusters [4-6]. The doping with other metal atoms like $\mathrm{Co}, \mathrm{Fe}, \mathrm{Mn}, \mathrm{Ni}, \mathrm{Ti}, \mathrm{Zr}, \mathrm{He}, \mathrm{Al}$ and $\mathrm{Ru}$ were also investigated [2,3,820]. All of these studies have provided important information on the physical and chemical properties of the TM doped germanium cagelike system together with their evolution as a function of size and composition. They show that the changes in properties of the host 
germanium structures are strongly related to the nature of the guest metal atom. Generally, the stability of the structure is enhanced with the encapsulation of a transition metal atom. Tran et al. [21-23] have published several joint experimental and computational investigations of the stability and geometrical and electronic structures of very small neutral and anionic clusters of $\mathrm{VGe}_{\mathrm{n}}{ }^{-/ 0}$ and $\mathrm{CoGe}_{\mathrm{n}}{ }^{-/ 0}$, they especially showed that multiconfigurational post-Hartree methods reproduce well the experimental electron detachment energies. First principles calculations have been performed by Wang et al. to study the doping with $\mathrm{Co}, \mathrm{Ni}$, or $\mathrm{W}$ atom in a small germanium cage clusters [24-26]. While the encapsulation of a transition metal atom into germanium cage generally enhances the stabilities, the growth patterns depend on the doping metal atom. Chromium-doped germanium clusters were the subject of several studies [27-30], which showed that the magnetic behavior of the ground state structure is highly affected by the metal atom. Very recently, investigations on germanium cage clusters doped with $\mathrm{V}, \mathrm{Cu}, \mathrm{Ag}$ and $\mathrm{Au}$ atoms have highlighted a large stability of some clusters, such as $\mathrm{VGe}_{14}, \mathrm{CuGe}_{10,12,14}$, $\mathrm{AgGe}_{12,14,15}, \mathrm{AuGe}_{12,14,15}$, which is related to their quasi-spherical geometry and to their peculiar electronic structure in which the valence electrons of metal and Ge atoms are delocalized and exhibit a shell structure [31,7]. Similar results were found for anionic gold-doped Ge [32].

Despite the relative abundance of investigations on the structural and electronic properties of small metal-doped germanium clusters, and to the best of our knowledge, systematic investigations of Palladium (Pd) and Platinum (Pt) doped germanium clusters have not been reported to date. It is questionable whether the doping with Pt and Pd, two elements belonging to the d-block beside noble metals on the periodic table, will lead to a somewhat metallic character where valence electrons occupy orbitals fully delocalized over the whole volume of the cluster, as previously reported for coinage metal doped $\mathrm{Ge}_{n}$ clusters [7], or conversely to chemical bonds and hybridization involving more localized orbitals as expected for open d-shell elements.

Here, we investigate the structural, electronic and optical properties of $\mathrm{MGe}_{\mathrm{n}}(\mathrm{M}=\mathrm{Pd}, \mathrm{Pt}$ and $n=1-20$ ) clusters by performing density-functional theory (DFT) calculations. The theoretical method is detailed in section 2, while results and a discussion are presented in sections 3 and 4 respectively.

\section{Computational methodology}

We have used the spin polarized density functional theory (DFT) within the generalized gradient approximation (GGA) parameterized by Perdew, Burke and Ernzerhof (PBE) [33] implemented in the SIESTA simulation code [34]. The norm conserving Troullier-Martins pseudopotentials [35] was used for all species. The optimization of the structures was obtained by self-consistent solving of the Kohn-Sham equations with a convergence criterion of $10^{-4}$ a.u. on the energy and electron density. Using the conjugate gradient (CG) algorithm, the geometries were optimized without any symmetry constraints, and a large supercell of $40 \AA$ side-length was used to avoid the interaction between neighboring clusters. Geometrical optimizations were considered as converged when the residual forces were smaller than $10^{-3} \mathrm{eV} / \AA$. Double zeta basis set (DZ) was used for Ge while double zeta basis including polarization functions (DZP) were used for both Pd and Pt species. In the Brillouin zone sampling, only the gamma-point $(\Gamma)$ was used for the $\mathrm{k}$ grid integration. The current calculation scheme performed on the $\mathrm{Ge}_{2}$ dimer gives a bong length of $2.450 \AA$ and a dissociation energy of $1.446 \mathrm{eV} /$ atom, in good agreement with the experimental data of $2.44 \AA$ [36] and $\sim 1.35 \mathrm{eV}$ [37] respectively. 
A large number of possible initial structures have been relaxed for each size. Amongst them, some initial structures of $\mathrm{Ge}_{\mathrm{n}+1}$ and metal-doped $\mathrm{Ge}_{\mathrm{n}}$ clusters were taken from literature [7, 31 and references therein]. Also, the putative structures of $\mathbf{M G e}_{\mathrm{n}}$ were obtained by local relaxation after the substitution of one $\mathrm{Ge}$ atom by $\mathrm{M}$ atom in several isomers of the original pure $\mathrm{Ge}_{\mathrm{n}+1}$ cluster. The different initial positions of the $\mathrm{Ge}$ atom in the $\mathrm{Ge}_{\mathrm{n}+1}$ clusters lead to different $\mathrm{MGe}_{\mathrm{n}}$ isomers. But the search for the lowest isomer cannot include a global optimization procedure of the potential energy surface, and we cannot be sure that a more stable structure than those found in our calculations does not exist. Here, we only show the lowestenergy isomers for each cluster size. The spin on the metal is found to be quenched, as in the case of $\mathrm{NiGe}_{n}[5,25]$, and the spin state of all low-lying structures is found to be singlet. Triplet states are found to lie at more than $0.1 \mathrm{eV} /$ atom above the lowest-energy singlet state.

Further analysis of the electronic properties and molecular orbitals have been performed with the software Gaussian09 [38] using PBE and the Gaussian-type basis sets cc-pvtz for Ge and LanL2DZ for Pd and Pt atoms. Optical absorption spectra are calculated in the framework of the Time-Dependent DFT (TDDFT) using the PBE functional and the range-separated hybrid functional $\omega \mathrm{B} 97 \mathrm{x}$ which includes an increasing amount of Hartree-Fock exchange at long-range (16\% at short-range and $100 \%$ at long-range) [39]. $\omega \mathrm{B} 97 \mathrm{x}$ is became very popular as it is expected to give a more suitable description of excitations in the adiabatic linear-response approximation currently used in TDDFT calculations [40]. Post-processing operations were performed using the graphical interface Gabedit [41].

\section{Results}

\subsection{Structural properties}

The ground state isomers of $\mathrm{PdGe}_{\mathrm{n}}$ and $\mathrm{PtGe}_{\mathrm{n}}$ clusters are showed in Figures 1 and 2 respectively. More low-energy isomers are given in Figure S1 and S2 in Supplemental material. Some physical parameters such as symmetry group, binding energy $\mathrm{E}_{\mathrm{b}}(\mathrm{eV} /$ atom), HOMOLUMO gaps (highest occupied-lowest unoccupied molecular orbital energy gap), vertical ionization potential (VIP) and electron affinity (VEA), and chemical hardness $\eta$ are reported in Table 1 and 2 for $\mathrm{PdGe}_{n}$ and $\mathrm{PtGe}_{\mathrm{n}}$ clusters respectively. Data for others isomers can be found in Supplemental informations (Tables S1 and S2). For smaller size, the metal is located on a peripheral position at the surface. The endohedral structures where the metal is totally encapsulated inside a germanium cage appear at $\mathrm{n}=10$ and 11 when the dopant is $\mathrm{Pd}$ and $\mathrm{Pt}$ respectively. So, the transition process in which the $\mathrm{M}$ atom moves from the surface to interior of the germanium cage appears at relative small size. For comparison this transition from exohedral to endohedral structure is observed at $\mathrm{n}=12$ in the case of doping with $\mathrm{Ag}$ and $\mathrm{Au}$ [7].

Now we describe briefly the structures of the most stable isomers for each species. The PdGe and PtGe diatomics have a bond length of 2.349 and $2.364 \AA$ respectively, which are shorter that the corresponding bond distance $2.450 \AA$ in the pure $\mathrm{Ge}_{2}$ dimer [31]. Also the binding energy of PdGe and PtGe calculated at 1.292 and $1.201 \mathrm{eV} /$ atom are lower than the that of the $\mathrm{Ge}_{2}$ dimer $(1.446 \mathrm{eV})$. The lowest energy isomer of $\mathrm{PdGe}_{2}$ and $\mathrm{PtGe}_{2}$ have a triangular structure with $\mathrm{C}_{2 \mathrm{v}}$ symmetry. A linear structure was also considered for this size but it is found to lie at higher energy comparatively to the $\mathrm{C}_{2 \mathrm{v}}$ triangular structure. The calculated $\mathrm{Ge}-\mathrm{Ge}$ and Ge-Pd bond lengths are 2.456 and $2.475 \AA$ respectively for $\mathrm{PdGe}_{2}$ and the calculated $\mathrm{Ge}-\mathrm{Ge}$ and Ge-Pt bond lengths are 2.468 and $2.533 \AA$ for $\mathrm{PtGe}_{2}$ clusters. The binding energy of $\mathrm{PdGe}_{2}$ 
and $\mathrm{PtGe}_{2}$ clusters are 0.082 and $0.004 \mathrm{eV} /$ atom larger than that of $\mathrm{Ge}_{3}$ clusters [31]. In the case of $\mathrm{PdGe}_{3}$ and $\mathrm{PtGe}_{3}$, planar rhombus structure with $\mathrm{C}_{2 \mathrm{v}}$ symmetry is the most stable isomers. The best structure for $\mathrm{PdGe}_{4}$ and $\mathrm{PtGe}_{4}$ is a distorted $\mathrm{Ge}_{4}$ rhombus with one capped $\mathrm{M}$ atom and belonging to the $\mathrm{C}_{2 \mathrm{v}}$ point group. For $\mathrm{PdGe}_{5}$ and $\mathrm{PtGe}_{5}$ clusters, a bicapped distorted $\mathrm{Ge}_{4}$ rhombus with $\mathrm{C}_{2 \mathrm{v}}$ symmetry is obtained as the ground state structure. The metal $\mathrm{M}(\mathrm{M}=\mathrm{Pd}, \mathrm{Pt})$ atoms capping a pentagonal pyramid $\mathrm{Ge}_{6}$ is the most stable structure for $\mathrm{MGe}_{6}$. For $\mathrm{n}=7$, the lowest-energy isomer differs with the metal dopant since the Pd atom caps the pentagonal bipyramid of $\mathrm{Ge}_{7}$, while two germanium atoms cap the distorted $\mathrm{PtGe}_{5}$ bipyramid with $\mathrm{C}_{\mathrm{s}}$ symmetry in the case of $\mathrm{PtGe}_{7}$. For $\mathrm{MGe}_{8}(\mathrm{M}=\mathrm{Pd}, \mathrm{Pt})$ clusters, three $\mathrm{Ge}$ atoms cap the $\mathrm{MGe}_{5}$ $(\mathrm{M}=\mathrm{Pd}, \mathrm{Pt})$ clusters in the lowest-energy isomer. By adding one $\mathrm{Ge}$ atom to cap one face on the most stable structure of $\mathrm{MGe}_{8}$ clusters, we obtain the most stable structure for $\mathrm{MGe}_{9}$ clusters. $\mathrm{Pt}$ atom caps a $\mathrm{Ge}_{10}$ cluster in the best structure for $\mathrm{PtGe}_{10}$ clusters.

Starting from $\mathrm{n}=10$ for $\mathrm{PdGe}_{\mathrm{n}}$ and from $\mathrm{n}=11$ for $\mathrm{PtGe}_{\mathrm{n}}$ clusters, all of the lowestenergy isomers exhibit a cage-like structure with the metal atom completely encapsulated, and highly coordinated at the center of the $\mathrm{Ge}_{\mathrm{n}}$ cage. A high symmetry $\mathrm{D}_{4 \mathrm{~d}}$ structure where $\mathrm{Pd}$ located at the center is coordinated with all atoms of the germanium cage is obtained for the best isomer of $\mathrm{PdGe}_{10}$. For $\mathrm{n}=11$, the structures obtained for Pd- and Pt-doped $\mathrm{Ge}_{11}$ are somewhat similar but differ by the symmetry $\left(\mathrm{C}_{5 \mathrm{v}}\right.$ for $\mathrm{PbGe}_{11}$, and $\mathrm{C}_{\mathrm{s}}$ for $\left.\mathrm{PtGe}_{11}\right)$. Pt- and $\mathrm{Pd}-$ $\mathrm{Ge}_{12}$ belong to the $\mathrm{S}_{4}$ symmetry point group. A spherical-like structure with a centered $\mathrm{Pd}$ atom is observed for $\mathrm{PdGe}_{13}$, while in the case of $\mathrm{PtGe}_{13}$, a Ge atom caps one face of the best isomer of $\mathrm{PtGe}_{12}$. For larger sizes $\mathrm{n}$, the growth pattern is somewhat similar for both metals while the lowest-energy isomers differ. For $\mathrm{n}=14,15$ and 16, the most stable structure for $\mathrm{MGe}_{\mathrm{n}}$ clusters is generally formed by one, two or three $\mathrm{Ge}$ atoms capping a spherical-like cage of $\mathrm{MGe}_{\mathrm{n}}$ where the $\mathrm{M}$ atom occupies the center of the $\mathrm{Ge}_{\mathrm{n}}$ cage. Adding one $\mathrm{Ge}$ atom at the surface of $\mathrm{MGe}_{14}$ (resp. $\mathrm{MGe}_{15}$ ) leads to the most stable structures of $\mathrm{MGe}_{15}$ (resp. $\mathrm{MGe}_{16}$ ). $\mathrm{PdGe}_{15,16}$ and $\mathrm{PtGe}_{15,16}$ have the larger binding energy among all size considered here. From $\mathrm{n}=17-20$, a distorted endohedral structure is observed for the lowest-energy isomer. The metal is encapsulated inside a germanium cage on which additional $\mathrm{Ge}$ atoms are attached at the surface.

\subsection{Energetics and electronic properties}

The binding energy is a good parameter for the study and the evaluation of the stability of small clusters. The average binding energy par atom is defined as:

$$
\left.E_{b}\left(M G e_{n}\right)=\left(n E(G e)+E(M)-E\left(M G e_{n}\right)\right)\right)(n+1),
$$

where $\mathrm{E}(\mathrm{Ge})$ and $\mathrm{E}(\mathrm{M})$ are the total energy of free $\mathrm{Ge}$ and $\mathrm{M}$ atoms respectively. $\mathrm{E}\left(\mathrm{MGe}_{\mathrm{n}}\right)$ is the total energy of the corresponding cluster. The size evolution of $E_{b}$ for the most stable structures of $\mathrm{PdGe}_{\mathrm{n}}$ and $\mathrm{PtGe}_{\mathrm{n}}$ clusters is shown is Figure 3. The binding energy of their corresponding pure germanium clusters [31] is plotted in the same figure for comparison. For all species, the value of $E_{b}$ increases with increasing size, which means that clusters gain in the stability during the growth process. For $\mathrm{n} \leq 6$, the doping does not systematically increase the binding energy in comparison with the corresponding $\mathrm{Ge}_{n+1}$ cluster. In contrast, for $n \geq 7$ the doping by the metal atom enhances considerably the stability of the host clusters. Thus, the doping $\mathrm{M}$ atom has no immediate effect on the stabilities of very small germanium clusters. This behavior can be related the structural properties of small $\mathrm{MGe}_{\mathrm{n}}(\mathrm{n}<7)$ clusters where the $\mathrm{M}-\mathrm{Ge}$ bond lengths are much larger than Ge-Ge bond lengths as we can see from Tables 1 and 2. The highest values of $E_{b}$ are obtained for $\mathrm{n}=12-16$, i.e. when the endohedral structures 
appear. Relative high values of the binding energy are observed for $\mathrm{n}=12,16$ and 18 which means that the corresponding $\mathrm{MGe}_{\mathrm{n}}$ clusters exhibit high stability comparatively to their neighbors.

The second energy difference is one of important parameter in clusters physics which can be used to evaluate the relative stability of one cluster size comparatively to their neighboring size. It is defined by:

$$
\Delta_{2} E=E\left(M G e_{n+1}\right)+E\left(M G e_{n-1}\right)-2 E\left(M G e_{n}\right)
$$

where $\mathrm{E}$ is the total energy of the ground state cluster. Calculated second energy differences as a function of the size for the best isomers are shown in Figure 4. A pronounced maximum is found at $\mathrm{n}=4,7,10,12,16$ and 18 . This indicates that these clusters have specific stabilities comparatively to their neighbors.

The HOMO-LUMO gap can give information about the stability of clusters and their chemical activity. In general, a large HOMO-LUMO gap implies a low chemical activity and a high chemical stability, while the latter decreases as the HOMO-LUMO gap decreases. The evolution of the calculated HOMO-LUMO gap of each species studied here is showed in Figure 5. In contrast to the roughly decreasing tendency of the evolution of HOMO-LUMO gaps for pure $\mathrm{Ge}_{\mathrm{n}}$ clusters, an oscillating behavior is observed for Pd- and Pt-Ge $\mathrm{C}_{\mathrm{n}}$ clusters. As expected, the gap of very small metal-doped $\mathrm{Ge}_{\mathrm{n}}$ is lower than that of the pure germanium clusters, but for $\mathrm{n} \geq 10$ the presence of the metal generally increases the HOMO-LUMO gap. This somewhat surprising behavior is due to the encapsulation of the metal into the Ge structure which stabilizes the electronic structure by absorbing the dangling bonds. Values oscillate in the 0.5-2.0 eV range, but the evolution with cluster size shows a non-monotonic behavior. Pronounced values of HOMO-LUMO gaps are observed for $\mathrm{PdGe}_{7,9,16,18}$ and $\mathrm{PtGe}_{7,10,16,18}$ which indicates that theses clusters have probably a lower reactivity than their neighbors.

Other parameters that are generally calculated in order to gain an insight into the electronic structure are the vertical ionization potential (VIP) and electron affinity (VEA). They are defined with the following formulas:

$$
\begin{aligned}
& V I P=E\left(M G e_{n}{ }^{+}\right)-E\left(M G e_{n}\right), \\
& V E A=E\left(M G e_{n}\right)-E\left(M G e_{n}{ }^{-}\right),
\end{aligned}
$$

where $E\left(M G e_{n}^{-}\right)$and $E\left(M G e_{n}{ }^{+}\right)$are the energy of the anionic and cationic $\mathrm{MGe}_{\mathrm{n}}$ clusters calculated using the geometrical structure of the neutral cluster. The VIP can give information about the capacity of a cluster to lose a valence electron. Values are in the 6.2-7.6 eV range. The evolution of VIPs for the ground state structure in each species are shown in Figure 6. We observe that VIPs show a decreasing evolution with an oscillating behavior as the cluster size increase. Local maxima are observed for $n=5,10,12,16,18$. The variation of the VEAs as a function of the size is plotted in Figure 7. The values of all species increase from 0.6 to $2.6 \mathrm{eV}$ with an oscillating behavior as the size increases. One can note the relative small value for doped $\mathrm{Ge}_{16}$ clusters. Both VIP and VEA are relatively little dependent on the nature of the doping metal. 
Another parameter that can be used to give more information about the relative stability of molecules and small clusters is the chemical hardness defined through the principle of maximum hardness $(\mathrm{PMH})$ of Pearson [42] as:

$$
\eta=\mathrm{VIP}-\mathrm{VEA}
$$

where VIP and VEA are the vertical ionization potential and electron affinity of the corresponding cluster. In general, a high value for $\eta$ indicates a high stability of the corresponding clusters. The evolution of $\eta$ with the cluster size $n$ are plotted in Figure 8. A relative high value is observed for $\mathrm{PdGe}_{5,7,16,18}$ and $\mathrm{PtGe}_{7,10,16,18}$ suggesting that these clusters should be less reactive than their neighbors, which is in total agreement with the predictions from the HOMO-LUMO gap analysis.

\section{Discussion}

Our results highlight a transition from exohedral to endohedral structures of $\mathrm{PdGe}_{\mathrm{n}}$ and $\mathrm{PtGe}_{\mathrm{n}}$ occurring at $\mathrm{n}=10$ and 11 respectively. This structural modification strongly affects the electronic properties. The atomic charges on metal atoms have been estimated through a natural population analysis (NPA) [43]. When Pd is located on a surface site, its atomic charge is relatively low (between -0.5 and -0.1 a.u.), but when the $M$ atom move to an endohedral position to be encapsulated inside the germanium, its charge strongly increases to about -1.6 a.u. or more (Table S3). Similarly, the atomic charge on $\mathrm{Pt}$ in $\mathrm{PtGe}_{\mathrm{n}}$ goes from about -0.4 to about -1.7 a.u. for the exohedral and endohedral structures respectively. The additional electrons captured by the metal atom in cage-like structure are mainly associated to $5 p$ or $6 p$ electron configurations. The large atomic charge indicate that the metal interacts with several $\mathrm{Ge}$ atoms, thus playing a stabilizing role of the $\mathrm{Ge}_{\mathrm{n}}$ cage.

The transition from exohedral to endohedral structure has been already observed at $\mathrm{n}=12$ in the case of $\mathrm{AgGe}_{\mathrm{n}}$ and $\mathrm{AuGe}_{\mathrm{n}}[7]$, at $\mathrm{n}=10$ for $\mathrm{CuGe}_{\mathrm{n}}$ [6,7], $\mathrm{VGe}_{\mathrm{n}}$ [3,31], $\mathrm{WGe}_{\mathrm{n}}$ [26], $\mathrm{NbGe}_{n}$ and $\mathrm{TaGe}_{n}$ [44], and at $\mathrm{n}=9$ for $\mathrm{NiGe}_{n}$ [5,25]. The encapsulated transition metal eliminates the dangling bonds of germanium atoms. In the present work, the cage-like structures enhance the binding energy, in particular for $n=12-16$.

Interestingly, $\mathrm{PdGe}_{16}$ and $\mathrm{PtGe}_{16}$ present a relatively high stability. They have the highest stability from both the binding energy (Figure 3 ) and the second-order energy difference (Figure 4). They also show a relatively high HOMO-LUMO gap (Figure 5), and a large chemical hardness (Figure 8). In Figure 9, we show the density of states (DOS) and the KohnSham orbitals calculated at PBE/cc-pvtz level with the software Gaussian09 [38] in the case of $\mathrm{PdGe}_{16}$. The 10 valence electrons of $\mathrm{Pd}$, and the $3 \mathrm{~s}$ and $3 \mathrm{p}$ valence electrons of Ge exhibit a shell structure associated to the somewhat spherical structure. We can easily distinguish the character of the orbitals, though there are some little deviations from a perfect sphere due to explicit location of atoms and the $\mathrm{C}_{\mathrm{s}}$ symmetry instead of $\mathrm{K}_{\mathrm{h}}$ (the symmetry of the atom). The 74 valence electrons of the cluster are organized with the following occupations: $1 S^{2} 1 \mathrm{P}^{6} 1 \mathrm{D}^{10}$ $1 \mathrm{~F}^{14} 2 \mathrm{D}^{10} 2 \mathrm{~S}^{2} 2 \mathrm{P}^{6} 1 \mathrm{G}^{18} 1 \mathrm{H}^{6}$. The number of electrons does not fit with shell closings numbers, but the pooling of electrons and the organization in shell contributes to the high stability of the cluster. Similar results are found for $\mathrm{PtGe}_{16}$.

In experiment, the geometrical structure is most often inaccessible, and the discrimination between endohedral and exohedral structures is generally highlighted by a 
measurement of discriminant physical or chemical properties. For example, the expected relatively low reactivity of endohedral structures has been used to highlight the formation of metal-doped germanium or silicium cages [45]. Neukermans et al. [1] have used the mass spectroscopy and interpret the high abundance $\mathrm{CuGe}_{10}$ in terms of peculiarly stable dopantencapsulated cage-like structures. More recently, several groups have used the photoelectron spectroscopy $[2,3,23]$. Here, we have calculated the UV-visible absorption spectra of both cagelike and surface-bound metal structures in order to discriminate endohedral and exohedral structures. Spectra are given in Figure $\mathrm{S} 3$ for $\mathrm{PdG}_{16}$ and $\mathrm{PdGe}_{10}$. Unfortunately, they are found to be only few dependent on the position of the metal atom, while the density of states is much higher in the case of surface-bound metal due to a lower symmetry of the structure. Spectra show a slowly increasing response in the visible and near UV domain, and a strong signal above $7 \mathrm{eV}$ (above the ionization potential). This low dependency of the absorption spectra on the geometrical can be explained by the electronic arrangement which tends to favor the pooling of valence electrons and the organization in shells where electrons occupy orbitals fully delocalized over the whole volume of the cluster. The shells are clearly visible in the case of symmetric structures, like cage-like structures (Figure 9 for example), but are no easily identifiable in the case of geometries without any symmetry like exohedral structures. The pooling of electrons is likely to be somewhat independent of the details of the structure, and consequently the optical absorption as well.

\section{Conclusion}

In summary, a theoretical investigation of the structural, stabilities and electronic properties of palladium- and platinum-doped germanium clusters has been carried out using the DFT method. Results are compared with the properties of pure $\mathrm{Ge}_{n}$ clusters.

From $\mathrm{n} \geq 10$ or 11 , the cage-like structures where the doping atom ( $\mathrm{Pd}$ or $\mathrm{Pt}$ ) is totally encapsulated at the center of $\mathrm{Ge}_{\mathrm{n}}$ cage are favored. The binding energy per atom, second-order difference of energies, HOMO-LUMO gaps, vertical ionization potential and electronic affinity and the chemical hardness have been studied as function of the cluster size. Our results show that measurements of optical absorption spectra are likely unable to discriminate the endohedral and exohedral structures.

The doping $\mathrm{M}$ atoms have no immediate effect on the stabilities of very small germanium clusters, but starting from $n=8$ the doping $M$ atom enhances considerably the stability of the host clusters. Our results highlight the relatively high stability of $\mathrm{PdGe}_{\mathrm{n}}$ and $\mathrm{PtGe}_{\mathrm{n}}$ clusters with specific sizes $\mathrm{n}=10,12,16$ and 18. Amongst, $\mathrm{PdGe}_{16}$ and $\mathrm{PtGe}_{16}$ are the most stable clusters. These clusters can be considered as a good candidate to be used as building blocks to make cluster assembled materials for eventual applications in the news nanotechnologies.

\section{Acknowledgements}

FR thanks the GENCI-IDRIS (Grant A0050807662) center for generous allocation of computational time.

\section{Data availability}

The raw/processed data required to reproduce these findings cannot be shared at this time due to technical or time limitations. 
Table 1. Symmetry group, binding energy $\mathrm{E}_{\mathrm{b}}(\mathrm{eV} / \mathrm{atom}), \mathrm{HOMO}-\mathrm{LUMO}$ gap $\Delta \mathrm{E}(\mathrm{eV})$, vertical ionization potential VIP $(\mathrm{eV})$, vertical electron affinity VEA $(\mathrm{eV})$, chemical hardness $\eta(\mathrm{eV})$ and average bond length $a_{G e-G e}(\AA)$ and $a_{P d-G e}(\AA)$ for PdGe $\mathrm{n}_{\mathrm{n}}$ clusters.

\begin{tabular}{|c|c|c|c|c|c|c|c|c|}
\hline Size (n) & Sym. & $\begin{array}{c}\text { Eb } \\
\text { (eV/atom) }\end{array}$ & $\Delta E(e V)$ & VIP $(e V)$ & VEA (eV) & $\eta(e V)$ & $a_{G e-G e}(\AA)$ & $a_{P d-G e}(\AA)$ \\
\hline PdGe & $\mathrm{C}_{\infty}$ & 1.292 & 0.597 & 6.599 & 0.693 & 5.906 & I & 2.349 \\
\hline $\mathrm{PdGe}_{2}$ & $\mathrm{C}_{2 \mathrm{v}}$ & 2.141 & 0.758 & 7.309 & 1.217 & 6.092 & 2.456 & 2.475 \\
\hline PdGe3 $_{3}$ & $\mathrm{C}_{2 \mathrm{v}}$ & 2.530 & 1.331 & 7.338 & 0.999 & 6.340 & 2.420 & 2.574 \\
\hline $\mathrm{PdGe}_{4}$ & $\mathrm{C}_{2 \mathrm{v}}$ & 2.738 & 1.328 & 7.450 & 1.259 & 6.191 & 2.610 & 2.698 \\
\hline PdGe5 & $\mathrm{C}_{\mathrm{s}}$ & 2.846 & 1.413 & 7.566 & 1.367 & 6.199 & 2.759 & 2.959 \\
\hline PdGe6 & $\mathrm{C}_{5 \mathrm{v}}$ & 2.924 & 1.007 & 7.458 & 2.027 & 5.431 & 2.737 & 2.824 \\
\hline $\mathrm{PdGe}_{7}$ & $\mathrm{C}_{\mathrm{s}}$ & 2.992 & 1.400 & 7.248 & 1.605 & 5.643 & 2.800 & 2.535 \\
\hline PdGe8 & $\mathrm{C}_{1}$ & 2.987 & 0.933 & 6.976 & 2.160 & 4.816 & 2.788 & 2.596 \\
\hline PdGe9 & $\mathrm{C}_{1}$ & 3.041 & 1.401 & 6.964 & 1.842 & 5.122 & 2.784 & 2.586 \\
\hline $\mathbf{P d G e}_{10}$ & $\mathrm{D}_{4 \mathrm{~d}}$ & 3.096 & 1.282 & 7.504 & 2.463 & 5.041 & 2.823 & 2.608 \\
\hline PdGe11 & $\mathrm{C}_{5 \mathrm{v}}$ & 3.126 & 1.054 & 6.958 & 2.158 & 4.800 & 2.766 & 2.716 \\
\hline PdGe $12_{2}$ & $\mathrm{~S}_{4}$ & 3.184 & 1.004 & 7.065 & 2.431 & 4.634 & 2.630 & 2.834 \\
\hline $\mathbf{P d G e}_{13}$ & $\mathrm{C}_{1}$ & 3.171 & 0.959 & 6.739 & 2.236 & 4.503 & 2.727 & 2.880 \\
\hline PdGe14 $_{14}$ & $\mathrm{C}_{\mathrm{s}}$ & 3.172 & 0.766 & 6.679 & 2.461 & 4.218 & 2.659 & 2.925 \\
\hline $\mathbf{P d G e}_{15}$ & $\mathrm{Cs}$ & 3.196 & 1.142 & 6.638 & 2.092 & 4.546 & 2.739 & 2.801 \\
\hline PdGe16 & $\mathrm{C} 2$ & 3.204 & 1.674 & 6.779 & 1.845 & 4.934 & 2.772 & 2.877 \\
\hline $\mathbf{P d G e}_{17}$ & $\mathrm{C} 1$ & 3.162 & 1.141 & 6.590 & 2.248 & 4.343 & 2.787 & 2.933 \\
\hline $\mathbf{P d G e}_{18}$ & $\mathrm{C} 1$ & 3.170 & 1.206 & 6.618 & 2.262 & 4.356 & 2.765 & 2.891 \\
\hline $\mathbf{P d G e}_{19}$ & $\mathrm{C} 3 \mathrm{v}$ & 3.142 & 1.008 & 6.415 & 2.305 & 4.110 & 2.703 & 2.917 \\
\hline $\mathbf{P d G e}_{20}$ & $\mathrm{C} 1$ & 3.155 & 1.068 & 6.625 & 2.548 & 4.076 & 2.723 & 2.844 \\
\hline
\end{tabular}


Table 2. Symmetry group, binding energy $\mathrm{E}_{\mathrm{b}}(\mathrm{eV} /$ atom), HOMO-LUMO gap $\Delta \mathrm{E}(\mathrm{eV})$, vertical ionization potential VIP $(\mathrm{eV})$, vertical electron affinity VEA $(\mathrm{eV})$,chemical hardness $\eta(\mathrm{eV})$ and average bond length $a_{G e-G e}(\AA)$ and $a_{P t-G e}(\AA)$ for $\mathrm{PtGe}_{\mathrm{n}}$ clusters.

\begin{tabular}{|c|c|c|c|c|c|c|c|c|}
\hline Size (n) & Sym. & $\begin{array}{c}\text { Eb } \\
\text { (eV/atom) }\end{array}$ & $\Delta E(\mathbf{E V})$ & VIP $(e V)$ & VEA $(\mathrm{eV})$ & $\eta(e V)$ & $a_{G e-G e}(\AA)$ & $a_{P t-G e}(\AA)$ \\
\hline PtGe & $\mathrm{C}_{\infty}$ & 1.201 & 1.635 & 6.826 & 0.624 & 6.202 & I & 2.364 \\
\hline $\mathrm{PtGe}_{2}$ & $\mathrm{C}_{2 \mathrm{v}}$ & 2.064 & 0.785 & 7.293 & 1.272 & 6.021 & 2.468 & 2.533 \\
\hline $\mathrm{PtGe}_{3}$ & $\mathrm{C}_{2 \mathrm{v}}$ & 2.477 & 1.329 & 7.308 & 1.011 & 6.297 & 2.427 & 2.629 \\
\hline $\mathrm{PtGe}_{4}$ & $\mathrm{C}_{2 \mathrm{v}}$ & 2.703 & 1.393 & 7.451 & 1.224 & 6.227 & 2.615 & 2.757 \\
\hline $\mathrm{PtGe}_{5}$ & $\mathrm{C}_{\mathrm{s}}$ & 2.802 & 1.326 & 7.519 & 1.431 & 6.088 & 2.833 & 3.001 \\
\hline PtGe $_{6}$ & $\mathrm{C}_{5 \mathrm{v}}$ & 2.902 & 1.049 & 7.440 & 1.982 & 5.458 & 2.741 & 2.740 \\
\hline $\mathrm{PtGe}_{7}$ & $\mathrm{C}_{\mathrm{s}}$ & 2.9596 & 1.574 & 7.242 & 1.456 & 5.787 & 2.772 & 2.719 \\
\hline PtGe8 & $\mathrm{C}_{1}$ & 2.9598 & 0.958 & 7.067 & 2.067 & 5.000 & 2.795 & 2.656 \\
\hline PtGe9 & $\mathrm{C}_{1}$ & 3.014 & 1.395 & 7.046 & 1.795 & 5.252 & 2.769 & 2.648 \\
\hline PtGe $_{10}$ & $\mathrm{C}_{1}$ & 3.064 & 1.753 & 7.243 & 1.640 & 5.603 & 2.795 & 2.605 \\
\hline PtGe $_{11}$ & $\mathrm{C}_{\mathrm{s}}$ & 3.086 & 0.919 & 7.008 & 2.370 & 4.638 & 2.672 & 2.806 \\
\hline PtGe $_{12}$ & $\mathrm{~S}_{4}$ & 3.169 & 0.9789 & 7.069 & 2.471 & 4.598 & 2.653 & 2.856 \\
\hline PtGe $_{13}$ & $\mathrm{C}_{\mathrm{s}}$ & 3.146 & 0.954 & 6.560 & 2.064 & 4.495 & 2.696 & 2.888 \\
\hline PtGe $_{14}$ & $\mathrm{C}_{1}$ & 3.176 & 0.857 & 6.519 & 2.247 & 4.272 & 2.664 & 2.947 \\
\hline PtGe $_{15}$ & $\mathrm{C}_{\mathrm{s}}$ & 3.189 & 1.179 & 6.615 & 2.037 & 4.578 & 2.751 & 2.892 \\
\hline PtGe $_{16}$ & $\mathrm{C}_{1}$ & 3.188 & 1.544 & 6.808 & 1.952 & 4.856 & 2.742 & 2.906 \\
\hline PtGe $_{17}$ & $\mathrm{C}_{1}$ & 3.151 & 1.145 & 6.571 & 2.235 & 4.337 & 2.800 & 2.956 \\
\hline PtGe $_{18}$ & $\mathrm{C}_{1}$ & 3.159 & 1.178 & 6.612 & 2.276 & 4.336 & 2.764 & 2.919 \\
\hline PtGe19 & $\mathrm{C}_{1}$ & 3.134 & 0.543 & 6.240 & 2.638 & 3.602 & 2.816 & 2.917 \\
\hline PtGe $_{20}$ & $\mathrm{C}_{1}$ & 3.143 & 0.809 & 6.415 & 2.592 & 3.824 & 2.704 & 2.949 \\
\hline
\end{tabular}




\section{References}

[1] Neukermans, S.; Wang, X.; Veldeman, N.; Janssens, E.; Silverans, R. E.; Lievens, P. Mass spectrometric stability study of binary $\mathrm{MS}_{\mathrm{n}}$ clusters $(\mathrm{S}=\mathrm{Si}, \mathrm{Ge}, \mathrm{Sn}, \mathrm{Pn}$, and $\mathrm{M}=\mathrm{Cr}, \mathrm{Mn}, \mathrm{Cu}$, Zn). Int. J. Mass Spectrometry 2006, 252, 145-150.

[2] Deng, X. J.; Kong, X. Y.; Xu, X. L.; Xu, H. G.; Zheng, W. J. Structural and Magnetic Properties of $\mathrm{CoGe}_{\mathrm{n}}^{-}[\mathrm{n}=2-11]$ Clusters: Photoelectron Spectroscopy and Density Functional Calculations. Chem. Phys. Chem. 2014, 15, 3987-3993.

[3] Deng, X.-J.; Kong, X.-Y.; Xu, H.-G.; Xu, X.-L.; Feng, G.; Zheng, W.-J. Photoelectron Spectroscopy and Density Functional Calculations of $\mathrm{VGe}_{\mathrm{n}}^{-}[\mathrm{n}=3-12]$ Clusters. J. Phys. Chem. C 2015, 119, 11048-11055.

[4] Bandyopadhyay, D.; Kaur, P.; Sen, P. New Insights into Applicability of Electron-Counting Rules in Transition Metal Encapsulating Ge Cage Clusters. J. Phys. Chem. A 2010, 114, 1298612991.

[5] Bandyopadhyay, D.; Sen, P. Density Functional Investigation of Structure and Stability of $\mathrm{Ge}_{\mathrm{n}}$ and $\mathrm{Ge}_{\mathrm{n}} \mathrm{Ni}(\mathrm{n}=1-20)$ Clusters: Validity of the Electron Counting Rule. J. Phys. Chem. A 2010, 114, 1835-1842.

[6] Bandyopadhyay, D. Architectures, Electronic Structures, and Stabilities of Cu-doped $\mathrm{Ge}_{\mathrm{n}}$ Clusters: Density Functional Modeling. J. Mol. Model. 2012, 18, 3887-3902.

[7] Mahtout, S.; Siouani, C.; Safer, S.; Rabilloud, F. Growth Behavior and Electronic Structure of Noble Metal-Doped Germanium Clusters. J. Phys. Chem. A 2018, 122, 662-677.

[8] Jing, Q.; Tian, F.; Wang, Y. No Quenching of Magnetic Moment for the $\mathrm{Ge}_{\mathrm{n}} \mathrm{Co}$ [n $=1-13$ ] Clusters: First Principles Calculations. J. Chem. Phys. 2008, 128, 124319.

[9] Zhao, W. J.; Wang, Y. X. Geometries, Stabilities, and Electronic Properties of FeGe $\mathrm{n}_{\mathrm{n}}[\mathrm{n}=$ 9-16] Clusters: Density-Functional Theory Investigations. Chem. Phys. 2008, 352, 291-296.

[10] Sosa-Hernandez, E. M.; Alvarado-Leyva, P. G. Magnetic Properties of Stable Structures of Small Binary $\mathrm{Fe}_{\mathrm{n}} \mathrm{Ge}_{\mathrm{m}}[\mathrm{n}+\mathrm{m} \leq 4]$ Clusters. Phys. E 2009, 42, 17-21.

[11] Zhao, W. J.; Wang, Y. X. Geometries, Stabilities, and Magnetic Properties of $\mathrm{MnGe}_{\mathrm{n}}[\mathrm{n}=$ 2-16] Clusters: Density-Functional Theory Investigations. J. Mol. Struct.: THEOCHEM 2009, $901,18-23$.

[12] Kapila, N.; Jindal, V. K.; Sharma, H. Structural, Electronic and Magnetic Properties of $\mathrm{Mn}, \mathrm{Co}, \mathrm{Ni}$ in $\mathrm{Ge}_{\mathrm{n}}$ for [n=1-13]. Phys. B 2011, 406, 4612-4619.

[13] Kumar, M.; Bhattacharyya, N.; Bandyopadhyay, D. Architecture, Electronic Structure and Stability of TM@ $\mathrm{Ge}_{\mathrm{n}}[\mathrm{TM}=\mathrm{Ti}, \mathrm{Zr}$ and Hf; $\mathrm{n}=1-20]$ Clusters: a Density Functional Modeling. J. Mol. Model. 2012, 18, 405-418.

[14] Shi, S.; Liu, Y.; Zhang, C.; Deng, B.; Jiang, G. A Computational Investigation of Aluminum-Doped Germanium Clusters by Density Functional Theory Study. Comput. Theor. Chem. 2015, 1054, 8-15.

[15] Jin, Y.; Tian, Y.; Kuang, X.; Lu, C.; Cabellos, J. L.; Mondal, S.; Merino, G. Structural and Electronic Properties of Ruthenium-Doped Germanium Clusters. J. Phys. Chem. C 2016, 120, 8399-8404. 
[16] Jaiswal, S.; Kumar, V. Growth behavior and electronic structure of neutral and anion $\mathrm{ZrGe}_{\mathrm{n}}$ [n = 1-21] clusters. Comput. Theor. Chem. 2016, 1075, 87-97.

[17] Lu, S.-J.; Hu, L.-R.; Xu, X.-L.; Xu, H.-G.; Chen, H.; Zheng, W.-J. Transition from exohedral to endohedral structures of $\mathrm{AuGe}_{\mathrm{n}}[\mathrm{n}=2-12]$ clusters: photoelectron spectroscopy and ab initio calculations. Phys. Chem. Chem. Phys. 2016, 18, 20321.

[18] Liang, X. Q.; Deng, X.J.; Lu, S.J.; Huang, X.; Zhao, J.; Xu, H.G.; Zheng, W.-J.; Zeng, X.C.. Probing Structural, Electronic and Magnetic Properties of Iron-doped Semiconductor Clusters $\mathrm{Fe}_{2} \mathrm{Ge}_{\mathrm{n}}{ }^{-10}[\mathrm{n}=3-12]$ via Joint Photoelectron Spectroscopy and Density-Functional Study, J. Phys. Chem. C 2017, 121, 7037-7046.

[19] S.E. Fioressi ; D.E. Bacelo. Structures and energetics of $\mathrm{Be}_{n} \mathrm{Ge}_{n}[\mathrm{n}=1-5]$ and $\mathrm{Be}_{2 n} \mathrm{Ge}_{\mathrm{n}}[\mathrm{n}$ = 1-4] clusters, Mol. Phys. 2017, 117, 1502-1513.

[20] Borshch, N.A.; Kurganskii, S.I.. Atomic Structure and Electronic Properties of Anionic Germanium-Zirconium Clusters. Inorg. Mat. 2018, 54, 1-7.

[21] Tran, V. T.; Nguyen, M.T.; Tran, Q.T., A Computational Investigation of the Geometrical and Electronic Structures of $\mathrm{VGe}_{\mathrm{n}}{ }^{-10}[\mathrm{n}=1-4]$ Clusters by Density Functional Theory and Multiconfigurational CASSCF/CASPT2 Method, J. Phys. Chem. A 2017, 121, 7787-7796.

[22] Tran, V. T.; Tran, Q.T., The Electronic Structures of $\mathrm{CoGe}_{n}{ }^{-10}[\mathrm{n}=1-3]$ Clusters from Multiconfigurational CASSCF/CASPT2 and RASSCF/RASPT2 Calculations, J. Phys. Chem. A 2018, 122, 6407-6415.

[23] Tran, V. T.; Tran, Q.T., Spin State Energetics of $\mathrm{VGe}_{\mathrm{n}}{ }^{-10}[\mathrm{n}=5-7]$ Clusters and New Assignments of the Anion Photoelectron Spectra. J. Comput. Chem. 2018, 39, 2103-2109.

[24] Wang, J.; Han, J. G. A Computational Investigation of Copper-Doped Germanium and Germanium Clusters by the Density-Functional Theory. J. Chem. Phys. 2005, 123, 244303.

[25] Wang, J.; Han, J. G. A Theoretical Study on Growth Patterns of Ni-Doped Germanium Clusters. J. Phys. Chem. B 2006, 110, 7820-7827.

[26] Wang, J.; Han, J. G. Geometries and Electronic Properties of the Tungsten-Doped Germanium Clusters: $W_{G e}$ [n = 1-17]. J. Phys. Chem. A 2006, 110, 12670-12677.

[27] Hou, X. J.; Gopakumar, G.; Lievens, P.; Nguyen, M. T. Chromium-Doped Germanium Clusters $\mathrm{CrGe}_{\mathrm{n}}[\mathrm{n}=1-5]$ : Geometry, Electronic Structure, and Topology of Chemical Bonding. J. Phys. Chem. A 2007, 111, 13544-13553

[28] Kapila, N.; Garg, I.; Jindal, V. K.; Sharma, H. First Principle Investigation into Structural Growth and Magnetic Properties in $\mathrm{Ge}_{\mathrm{n}} \mathrm{Cr}$ Clusters for $\mathrm{n}=1-13$. J. Magn. Magn. Mater. 2012, 324, 2885-2893.

[29] Mahtout, S.; Tariket, Y. Electronic and Magnetic Properties of $\mathrm{CrGe}_{\mathrm{n}}(15 \leq \mathrm{n} \leq 29)$ Clusters: A DFT Study. Chem. Phys. 2016, 472, 270-277.

[30] Liang, X.Q. ; Kong, X. ; Lu, S.J.; Huang, Y.; Zhao, J.; Xu, H.G.; Zheng, W.; Zeng, X.C.. Structural Evolution and Magnetic Properties of Anionic Clusters $\mathrm{Cr}_{2} \mathrm{Ge}_{\mathrm{n}}$ [n $\left.=3-14\right]$ : Photoelectron Spectroscopy and Density Functional Theory Computation. J. Phys. Condens. Matter, 2018, 30, 335501. 
[31] Siouani, C.; Mahtout, S.; Safer, S.; Rabilloud, F. Structure, Stability, and electronic and magnetic properties of $\mathrm{VGe}_{\mathrm{n}}(\mathrm{n}=1-19)$ clusters. J. Phys. Chem. A 2017, 121, 3540-3554.

[32] Bandyopadhyay, D. Electronic structure and stability of anionic $\mathrm{AuGe}_{\mathrm{n}}(\mathrm{n}=1-20)$ clusters and assemblies: a density functional modeling. Struct. Chem. 2019, 30, 955-963.

[33] Perdew, J.P., Burke, K.; Ernzerhof, M.; Generalized Gradient Approximation Made Simple, Phys. Rev. Lett. 1996, 77, 3865-3868.

[34] Soler, J.M.; Artacho, E.; Gale, J.D.; García,A.; Junquera, J.; Ordejón, P.; Sánchez-Portal, D. The SIESTA method for ab initio order-N materials simulation. J. Phys.: Condens. Matt., 2002, 14, 2745-2779.

[35] Troullier, N.; Martins, J.L.; Efficient pseudopotentials for plane-wave calculations, Phys. Rev. B 1991, 43, 1993.

[36] Gadiyak, G. V.; Morokov, Y. N.; Mukhachev, A. G.; Chernov, S. V. Electron Density Functional Method for Molecular System Calculations. J. Struct. Chem. 1982, 22, 670-674.

[37] Kingcade, J.E..; Nagarathna-Naik, H. M.; Shim, I.; Gingerich, K. A.; Electronic structure and bonding of the molecule $\mathrm{Ge}_{2}$ from all-electron $\mathrm{ab}$ initio calculations and equilibrium measurements, J. Phys. Chem. 1986, 90, 2830-2834.

[38] Frisch, M.J. et al., Gaussian09, Revision D.01, Gaussian Inc., Wallingford CT, 2013.

[39] Chai, J.-D.; Head-Gordon, M. Systematic optimization of long-range corrected hybrid density functionals. J. Chem. Phys. 2008, 128, 084106

[40] Rabilloud, F. Description of plasmon-like band in silver clusters: The importance of the long-range Hartree-Fock exchange in time-dependent density-functional theory simulations, $J$. Chem. Phys. 2014, 141, 144302.

[41] Allouche, A.R.; A Graphical user interface for computational chemistry software, $J$. Comput. Chem. 2011, 32, 174-182.

[42] Parr, R. G.; Yang, W. Density Functional Theory of Atoms and Molecules; Oxford University Press: New York, 1989;

[43] Reed, A.E; Weinhold, F. Natural bond orbital analysis of near-Hartree-Fock water dimer. J. Chem. Phys. 1983, 78, 4066

[44] Siouani, C.; Mahtout, S.; Safer, S.; Rabilloud, F. Structure, Stability, and electronic properties of niobium-germanium and tantalum-germanium clusters. J. Mol. Model. 2019, 25, 113.

[45] Sporea, C.; Rabilloud, F. Stability of alkali-encapsulated silicon cage clusters, J. Chem. Phys. 2007, 127, 164306. 

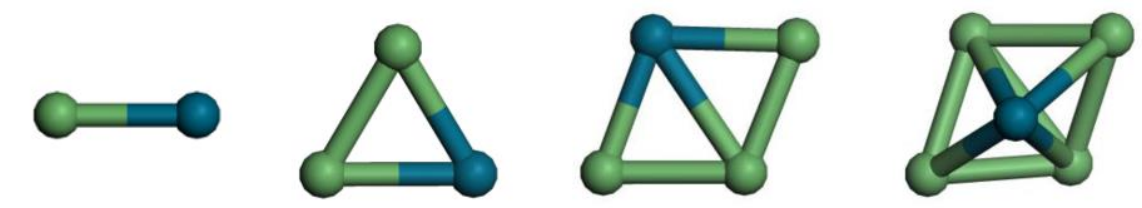

PdGe1

PdGe2

$\mathrm{PdGe}_{3}$

PdGe4
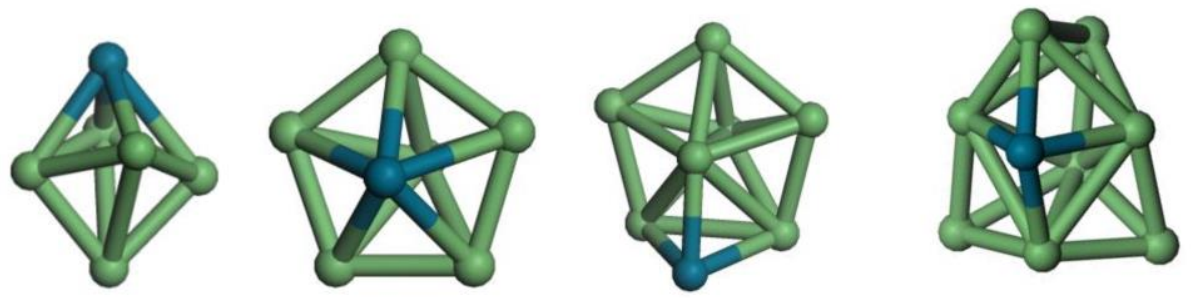

PdGe5

PdGe6

$\mathrm{PdGe}_{7}$

PdGes
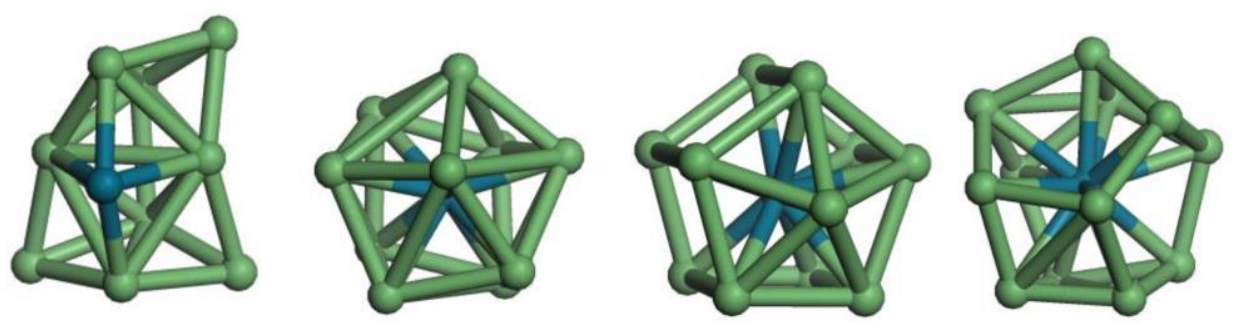

PdGe9

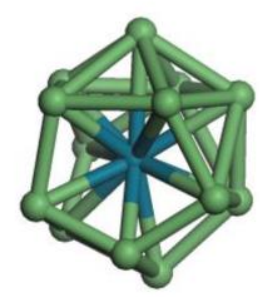

PdGe10

$$
\text { PdGe11 }
$$

PdGe12

PdGe13

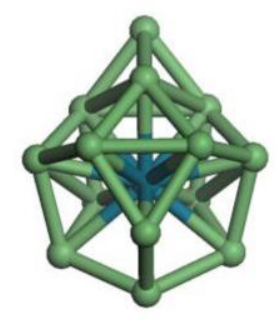

PdGe14

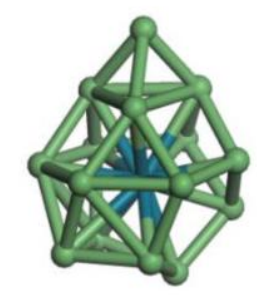

PdGe15

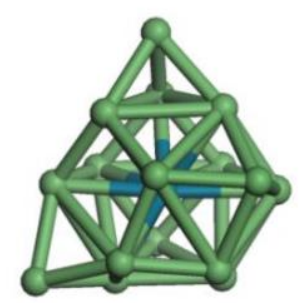

PdGe16

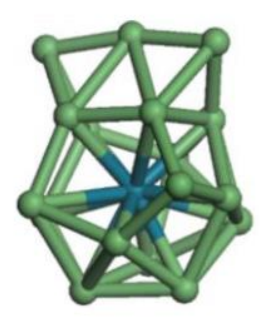

PdGe17

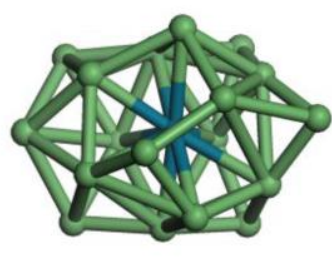

PdGe18

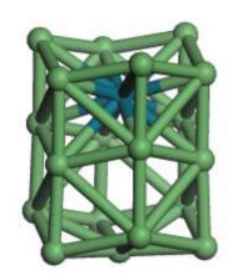

PdGe19

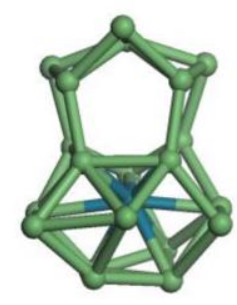

PdGero

Figure 1: Lowest-energy isomer for $\mathrm{PdGe}_{\mathrm{n}}(\mathrm{n}=1-20)$ clusters. 

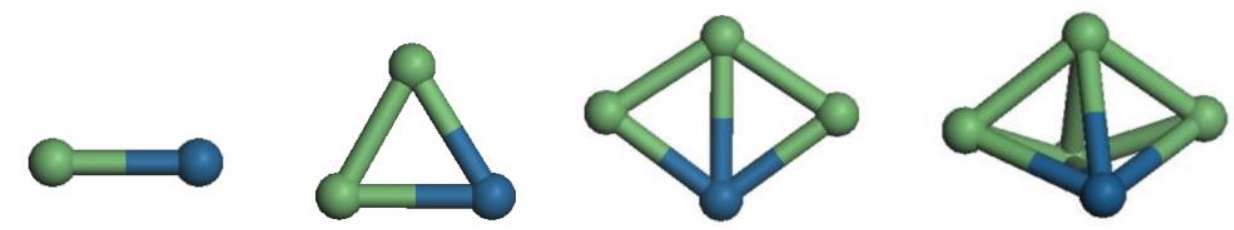

PtGe1

PtGe2

$\mathrm{PtGe}_{3}$

PtGe4
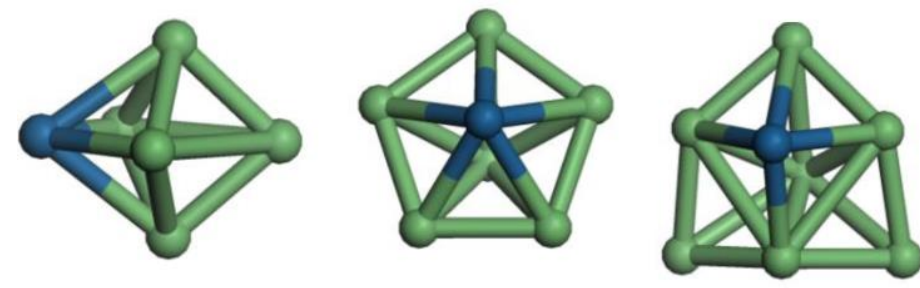

PtGe5

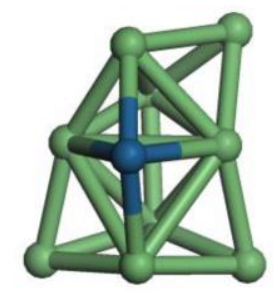

PtGe9

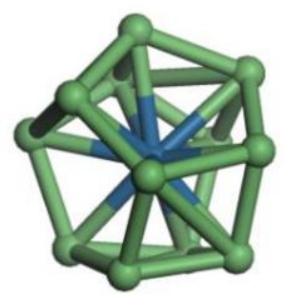

PtGe13

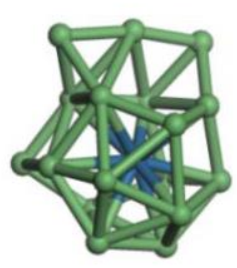

PtGe17

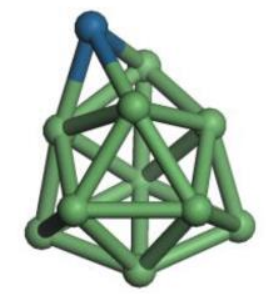

PtGe10

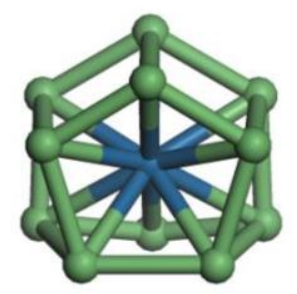

PtGe11

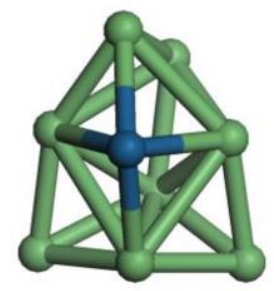

PtGe8

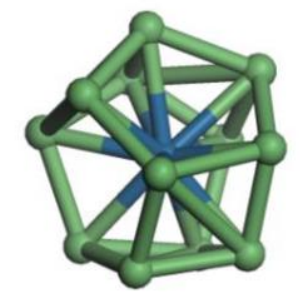

PtGe12

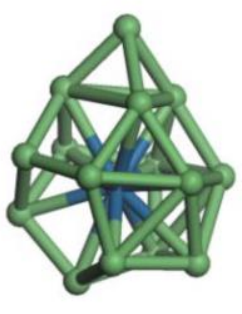

PtGe15

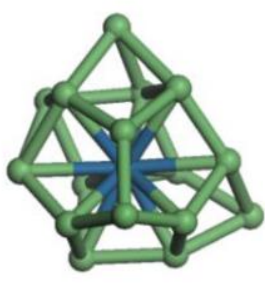

PtGe16

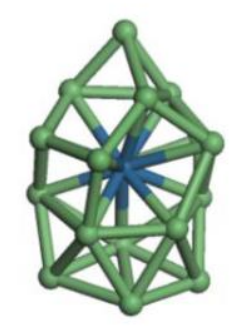

PtGe18

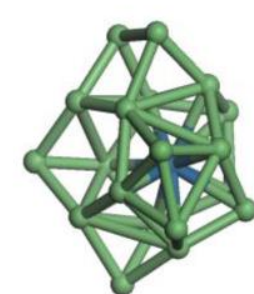

PtGe19

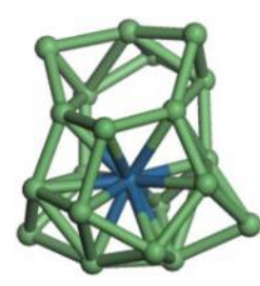

PtGe2o

Figure 2. Lowest-energy isomer for $\mathrm{PtGe}_{\mathrm{n}}(\mathrm{n}=1-20)$ clusters. 


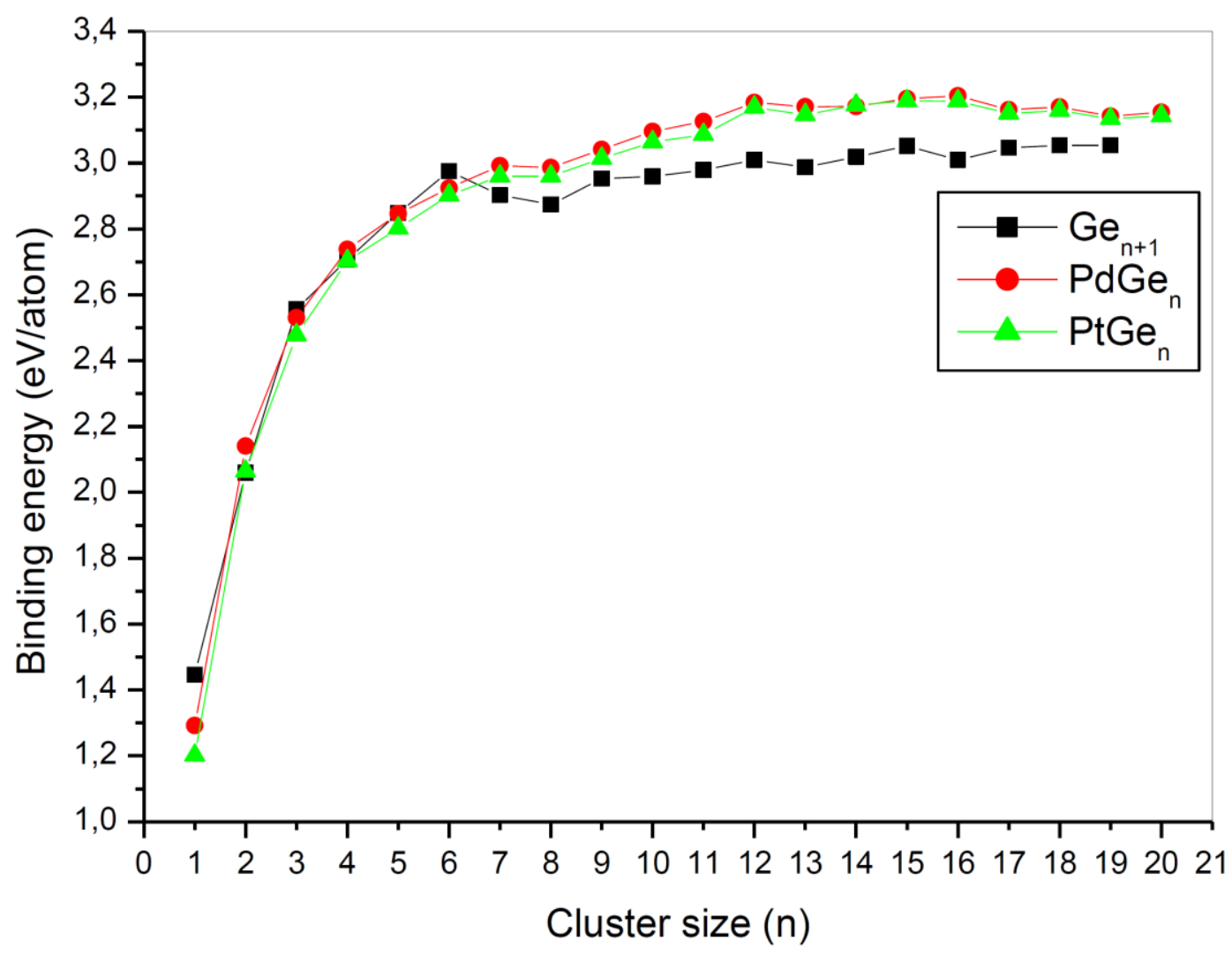

Figure 3. Binding energy per atom $\left(E_{b}\right)$ for the most stable isomer of $\mathrm{MGe}_{\mathrm{n}}(\mathrm{M}=\mathrm{Pd}$, $\mathrm{Pt}$ and $\mathrm{n}=1-20$ ) clusters. 


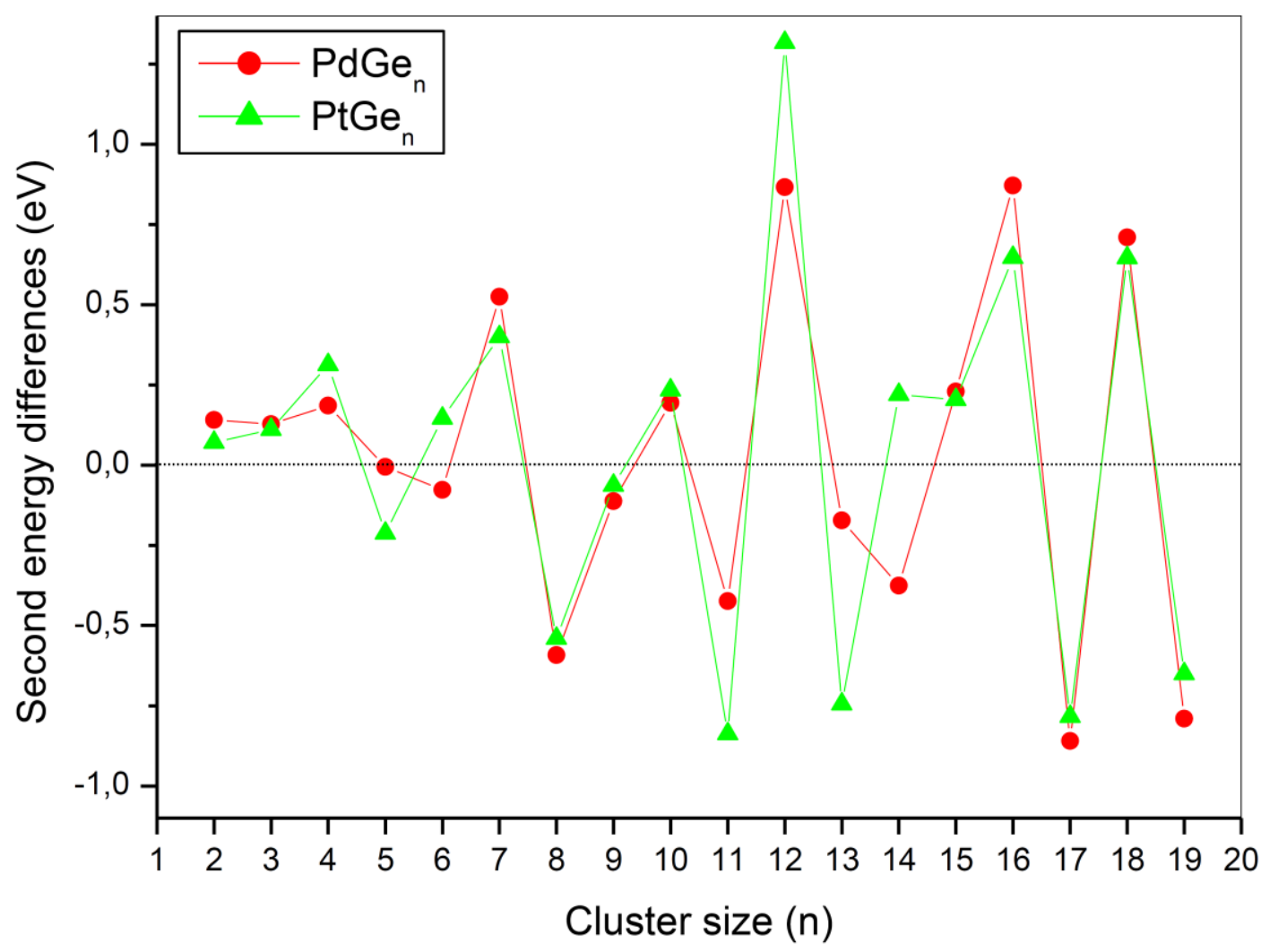

Figure 4. Second energy differences $\left(\Delta_{2} E\right)$ for the ground-state isomer of $\mathrm{MGe}_{\mathrm{n}}(\mathrm{M}=\mathrm{Pd}, \mathrm{Pt}$ and $n=1-20$ ) clusters. 


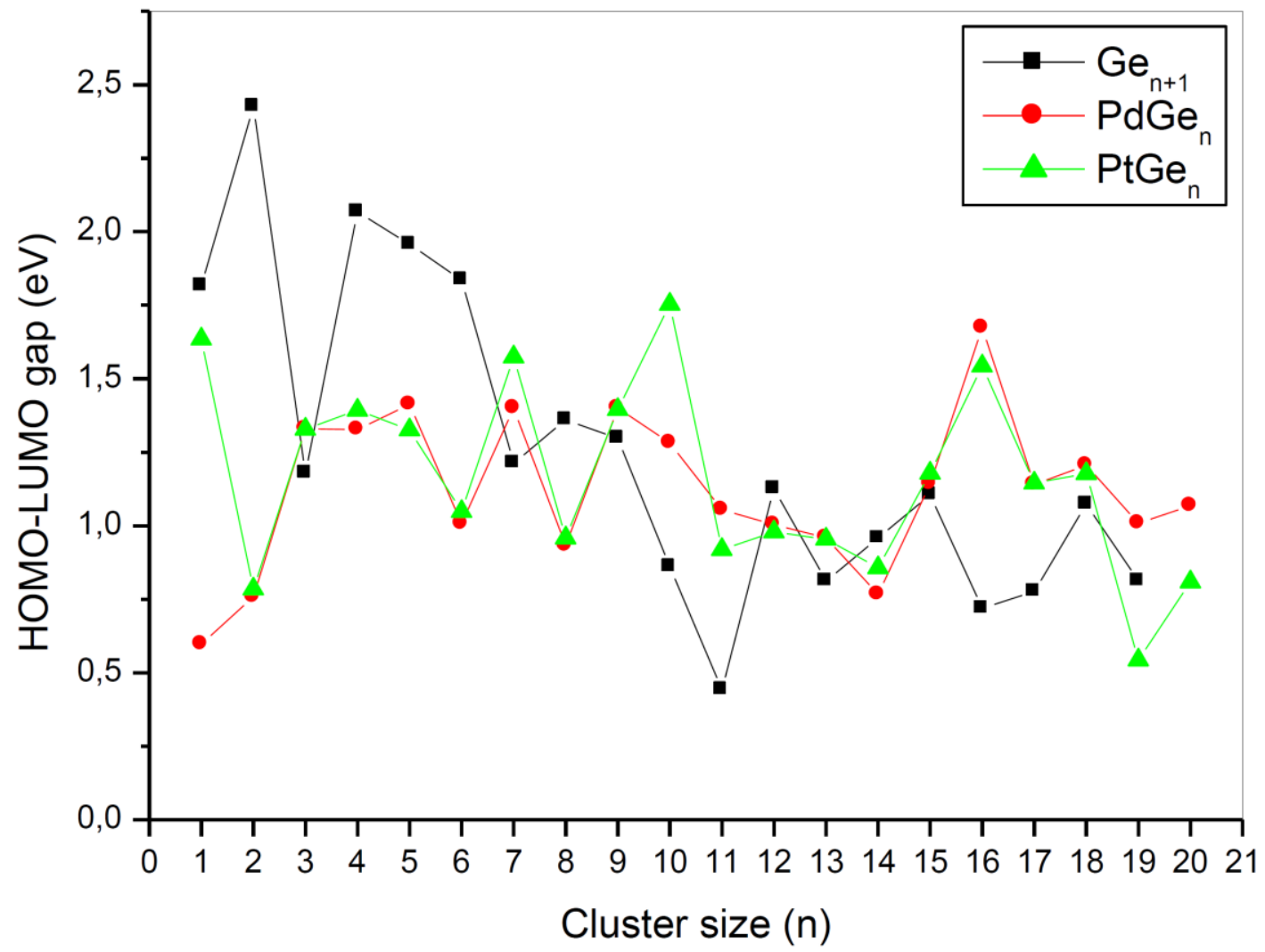

Figure 5. HOMO-LUMO gap $(\Delta \mathrm{E})$ for the ground-state isomer of $\mathrm{MGe}_{\mathrm{n}}(\mathrm{M}=\mathrm{Pd}, \mathrm{Pt}$ and $\mathrm{n}=1$ 20) clusters. 


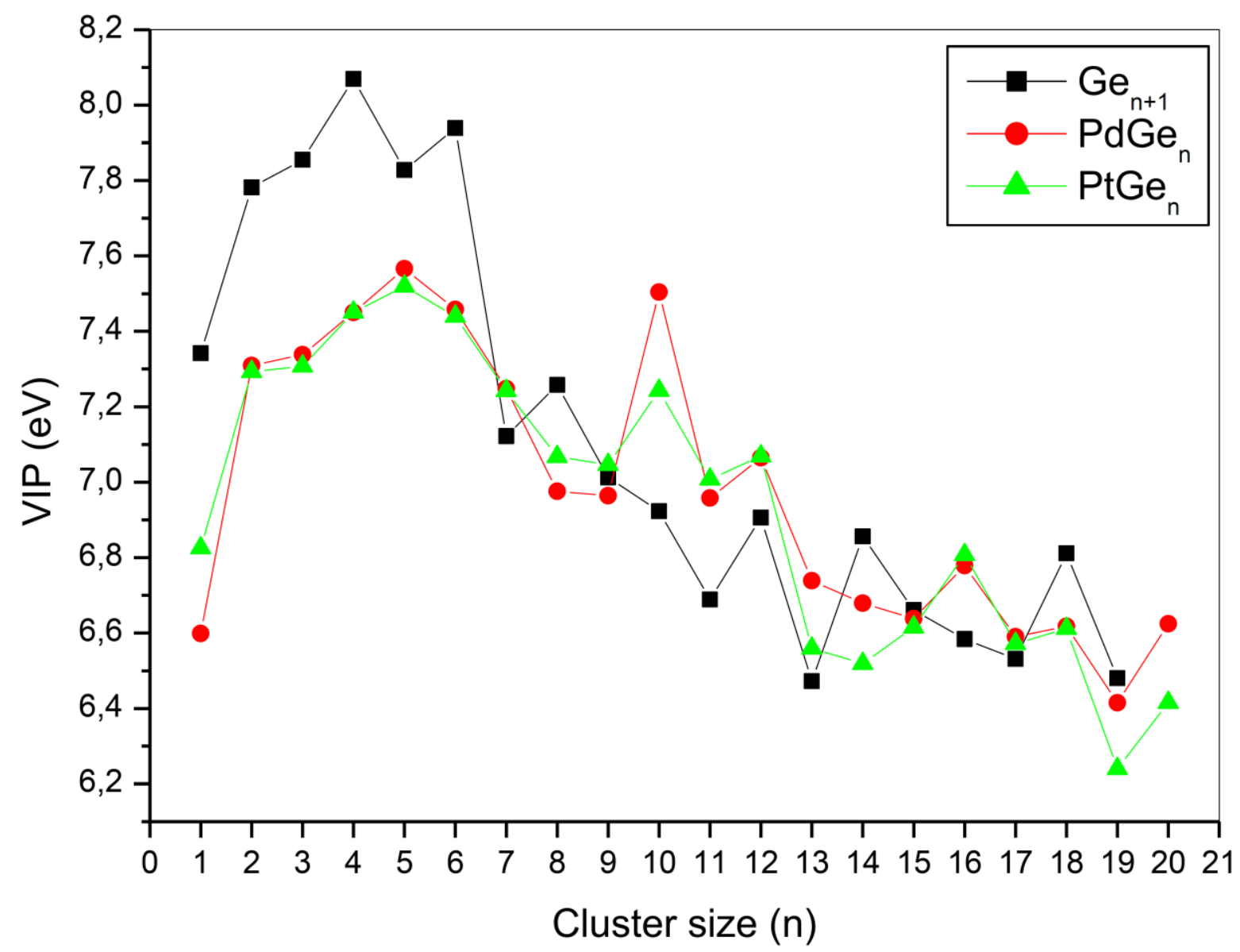




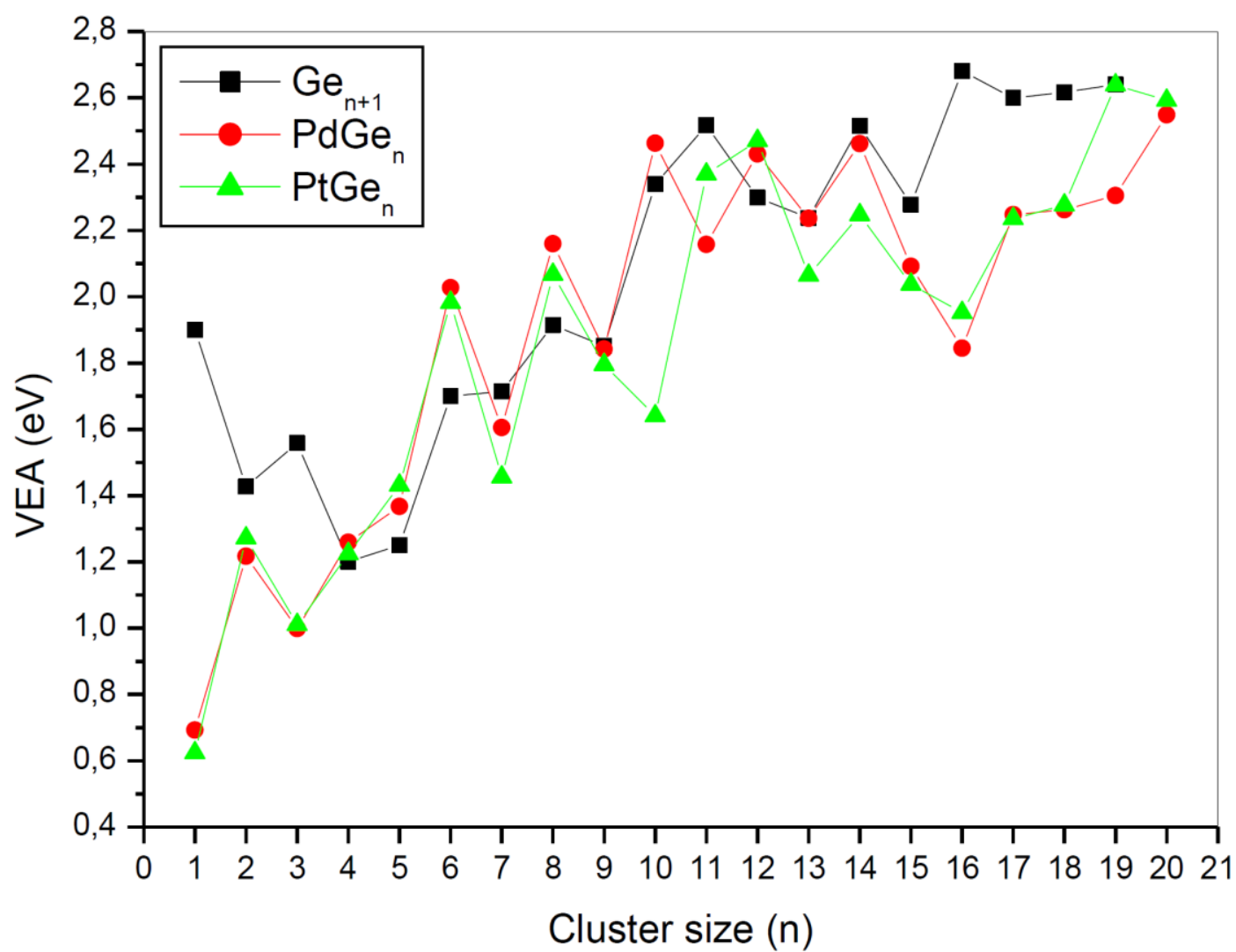

Figure 7. Vertical electron affinities (VEA) for the ground-state isomer of $\mathrm{MGe}_{n}(\mathrm{M}=\mathrm{Pd}, \mathrm{Pt}$ and $n=1-20$ ) clusters. 


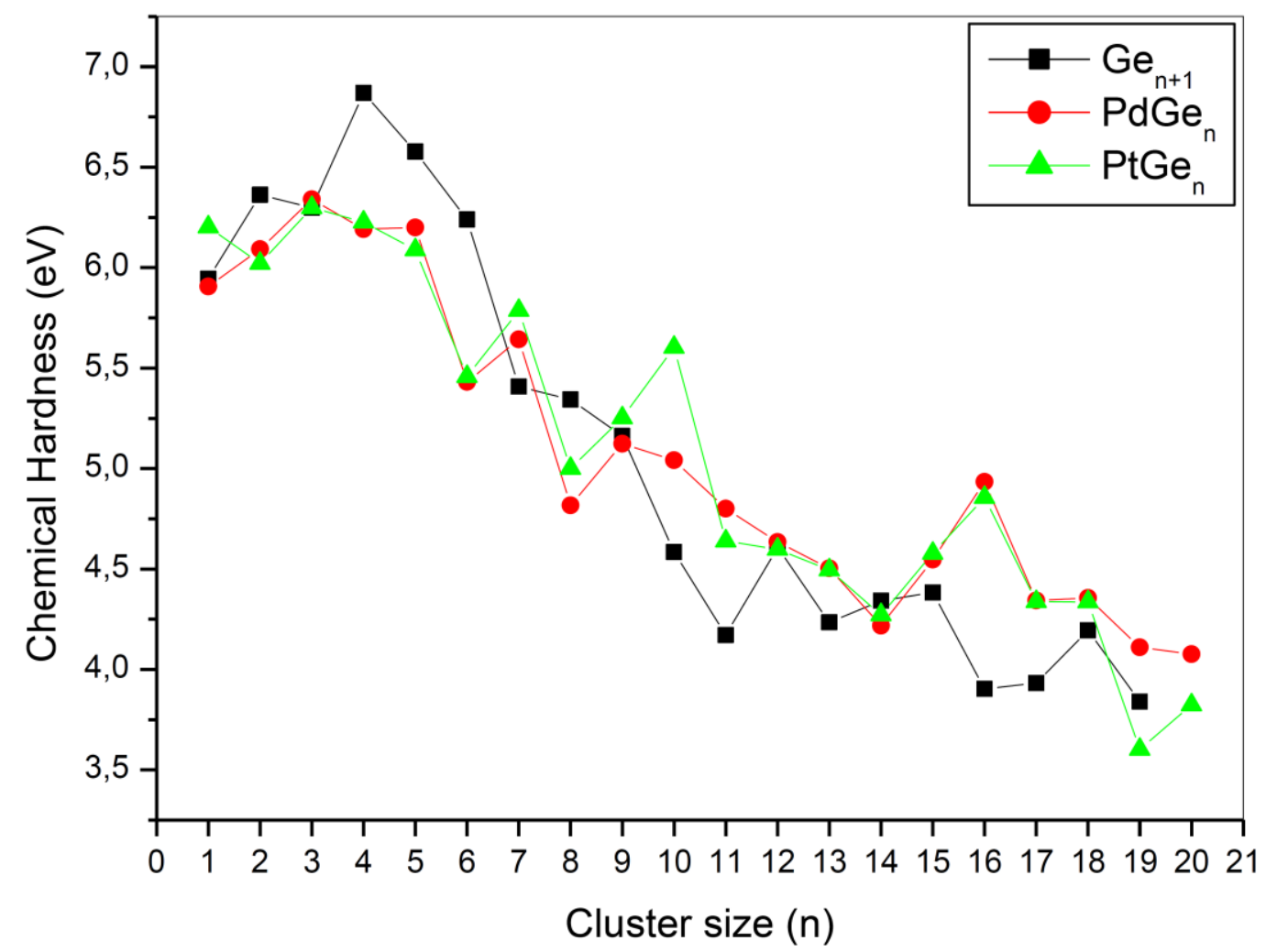

Figure 8. Chemical hardness $(\eta)$ for the ground-state isomer of $\mathrm{MGe}_{\mathrm{n}}(\mathrm{M}=\mathrm{Pd}, \mathrm{Pt}$ and $\mathrm{n}=1-20)$ clusters.

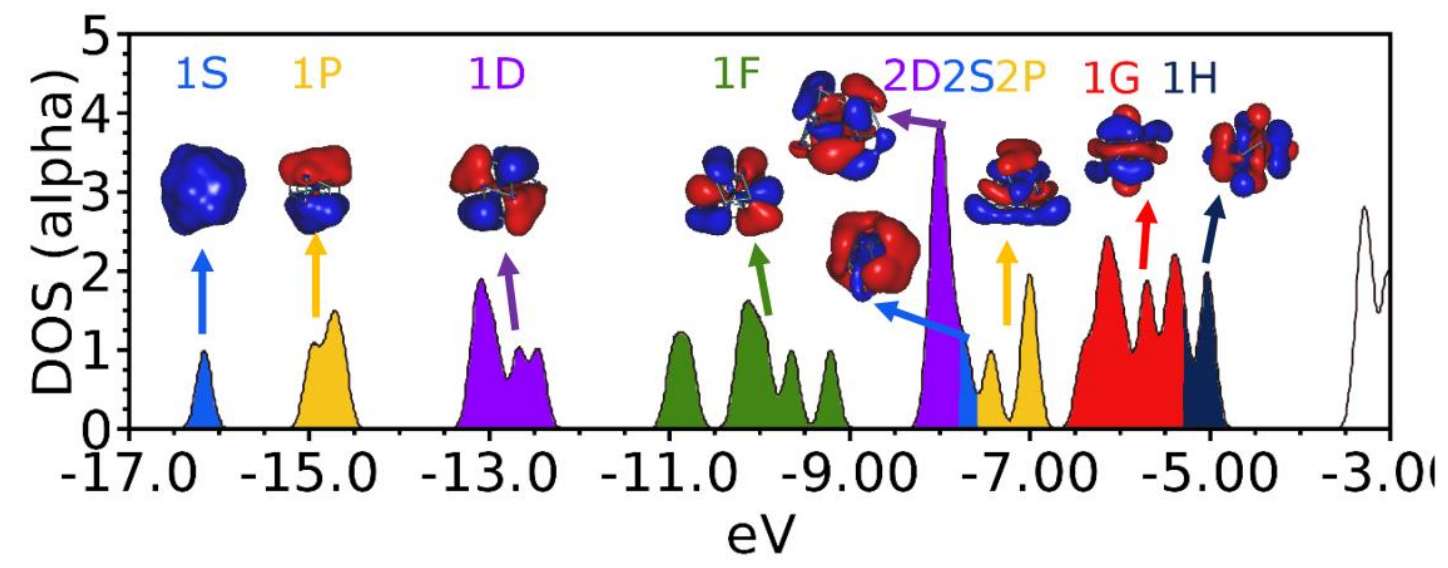

Figure 9. Density of states (DOS) of $\mathrm{PdGe}_{16}$ for alpha spin electrons. For each band, the KohnSham orbitals are plotted. The electronic structure shows a shell filling with the following sequence: $1 \mathrm{~S}^{2} 1 \mathrm{P}^{6} 1 \mathrm{D}^{10} 1 \mathrm{~F}^{14} 2 \mathrm{D}^{10} 2 \mathrm{~S}^{2} 2 \mathrm{P}^{6} 1 \mathrm{G}^{18} 1 \mathrm{H}^{6}$. 